\title{
El ingenio y la impostura: Enric Marco como desviación de don Quijote
}

\author{
Ingenuity and imposture: Enric Marco as a deviation from Don Quixote
}

\author{
Magdalena Pérez Facio \\ Consejo de Educación Secundaria (ANEP, Uruguay)
}

Resumen: En este artículo se pretende analizar la composición de Enric Marco — quien fue conocido como sobreviviente de los campos de concentración nazis hasta que en 2005 se descubrió su impostura-, como personaje de Javier Cercas en su novela El impostor, en relación al personaje de don Quijote. El autor plantea la interrogante de si es Marco un quijote del siglo XX. No pretendemos arribar a una respuesta, pero sí propiciar una reflexión al respecto. Para ello intentaremos identificar tanto las semejanzas y diferencias entre ambos personajes, como el orden en que Cercas elige plantear estas características y contar la historia de Marco teniendo siempre como referencia al personaje cervantino.

Palabras clave: Cercas, Marco, don Quijote, realidad, ficción, impostura.

Abstract: This article aims to analyze the composition of Enric Marco — who was known as a survivor of the Nazi concentration camps until his imposture was discovered in 2005- as a character of Javier Cercas in his novel El impostor, in relation to the character of Don Quixote. The author raises the question of whether Marco is a twentieth century Don Quixote. We do not intend to provide an answer, but we do intend to encourage reflection on it. To do this we will try to identify both the similarities and differences between the two characters, as well as the way in which Cercas chooses to present these characteristics and tell Marco's story always having the Cervantine character as a reference.

Keywords: Don Quixote, reality, fiction, imposture.

Recibido: $22 / 10 / 2020$

Aceptado: 08/01/2021

En mayo de 2005, impactó la noticia de que Enric Marco, uno de los mayores promotores de la memoria histórica en España, quien se había presentado públicamente durante décadas como sobreviviente de Flossenbürg y era en ese momento presidente de la Amical de Mauthausen en Barcelona, nunca había estado prisionero en un campo de 
concentración ${ }^{1}$. La noticia produjo en su momento una verdadera conmoción. Nueve años después del escándalo, Javier Cercas publicó su novela ${ }^{2}$ El impostor, en la que recoge la historia de Marco y pretende encontrar las verdades detrás de las mentiras — «porque una mentira solo triunfa si está amasada con verdades» (Cercas, 2014a: 43) —, y desentrañar así el enigma profundo: «¿Quién es Enric Marco?»³ (Cercas, 2014a: 410).

Javier Cercas tiene una forma particular de narrar que se aprecia en varias de sus novelas y que él mismo define de la siguiente manera: «Escribo novelas de aventuras sobre la aventura de escribir novelas» (Cercas, 2017). Tanto en Soldados de Salamina (2001) como en Anatomía de un instante (2009) o El monarca de las sombras (2017) podemos ver esa doble línea que recorre sus obras: en primer lugar, unas novelas de aventuras en las que asistimos a los hechos protagonizados por los personajes, pero también, y sobre todo, a un intento de comprender el móvil de su conducta; y, en segundo lugar, «la aventura de escribir una novela», en la que el autor nos muestra su propio proceso interior en la decisión de adentrarse en determinado hecho y su evolución durante el transcurso de la creación de la obra. Esto mismo sucede en El impostor. Por un lado, tenemos la historia de Marco, su impostura primero como sindicalista, anarquista, opositor a la dictadura de Franco y, más adelante, como deportado sobreviviente de los campos de concentración nazis. Por otro, asistimos a las cavilaciones del propio Cercas ${ }^{4}$, a sus cuestionamientos éticos sobre la conveniencia de escribir o no la historia de Marco y a la evolución en la relación con el hombre que en un comienzo le generó un rechazo indisimulable y que, sin embargo, acabó por despertarle cierta simpatía. Cercas intenta entender sin justificar y llegar a la verdad. Al mismo tiempo, se pregunta si es esto posible o si toda comprensión comporta, en cierta medida, una justificación. Su objetivo es hacer «una novela sin ficción» que nos permita analizar el

\footnotetext{
${ }^{1}$ El desenmascaramiento de Marco fue producto de un minucioso trabajo realizado por el historiador Benito Bermejo, quien desde la década de los noventa se había dedicado a la investigación sobre los deportados españoles en los campos nazis. En su momento se le atribuyeron un sinfín de intenciones políticas, pero Cercas plantea como único móvil evidente que Bermejo «era solo un historiador serio» (2014a: 309), un «francotirador» (2014a: 310) que ya había descubierto, junto a su colega Sandra Checa, al también impostor Antonio Pastor Martínez.

${ }^{2}$ Tomaremos el concepto de novela según el propio Cercas lo aplica a su obra Anatomía de un instante en El punto ciego: «aunque solo sea porque, desde Cervantes, a este tipo de libros mestizos solemos llamarlos novelas» (2015a: 28), partiendo de que la novela es un «género de géneros donde caben todos los géneros y se alimenta de todos» (2015a: 26) y que ha fagocitado «épica, historia, poesía, ensayo, periodismo» (2015a: 27) entre otros.

${ }^{3}$ Si bien esta es la pregunta inicial, a lo largo de la novela Cercas dejará interrogantes sin resolver — porque no puede o no quiere hacerlo-, como si estuvo o no Marco en Mallorca con su tío Anastasio. Ante la súplica de Marco: «Por favor, déjame algo», el autor cede: «Le dejo eso» (Cercas, 2014a: 91), sin que esta falta de resolución afecte en nada el propósito inicial, porque «la novela es el género de las preguntas, no el de las respuestas» (Cercas, 2015a: 55).

${ }^{4}$ La novela presenta un narrador en primera persona cuyo nombre coincide con el del autor, por lo cual, siendo conscientes de este juego metaficcional, asumiremos a efectos de este trabajo la identificación intencional entre el personaje, el narrador y el autor. Teniendo en cuenta los aportes seminales de Lejeune (1994), puede profundizarse en este aspecto concreto de El impostor en Pozo García (2018).
} 
entramado de mentiras que tejen la historia del falso deportado. Así lo expresa Cercas (2014c) en una entrevista con El periódico: "Todo lo que hay en este libro es verdad, la ficción la pone Marco» ${ }^{5}$ (párr. 30).

La vinculación entre este personaje - asumiendo que lo es tanto en la vida real como en la novela de Cercas - y el cervantino por excelencia, don Quijote de la Mancha, queda planteada en el libro desde las primeras páginas: «Enric es igual que don Quijote: no se conformó con vivir una vida mediocre y quiso vivir una vida a lo grande» (Cercas, 2014a: 33). Habida cuenta de esto, en nuestro trabajo se pretende abordar la relación entre El Quijote y El impostor en dos aspectos claves: por un lado, las similitudes entre Marco y don Quijote ${ }^{6}$; por otro, el orden que elige Cercas para contar la historia de Marco, y su rol como narrador.

El primer punto es acaso el más evidente. Las similitudes entre Marco y don Quijote son enunciadas en muchísimas oportunidades y por diferentes personajes a lo largo de $E l$ impostor. Ambos, llegados a un momento en el que se sienten insatisfechos con su realidad y saben que ya no les queda mucho tiempo, deciden dar un giro radical a su existencia, dejar atrás esa vida gris, ya sea de hidalgo o de mecánico, y lanzarse a la búsqueda de la gloria, a la empresa de ser un héroe. Dice Cercas:

A los cincuenta años de edad, don Quijote y Marco se rebelan contra su destino natural, que es, pasada la cumbre de la vida, darse por satisfechos con lo que han vivido y prepararse para la muerte; ellos no condescienden, no se resignan, no se someten, ellos quieren seguir viviendo, quieren vivir más, quieren vivir todo aquello que nunca vivieron y que siempre soñaron con vivir. Están dispuestos a todo para conseguirlo; a todo significa a todo: también a engañar al mundo haciéndole creer que son el gran Quijote y el gran Enric Marco. Entre la verdad y la vida, eligen la vida: si la mentira da vida y la verdad mata, ellos eligen la mentira; si la ficción salva y la realidad mata, ellos eligen la ficción. (2014a: 232)

Asimismo, es interesante el paralelismo en el proceso de esta transformación. En el capítulo inicial de El Quijote se narra que Alonso Quijano sintió deseos de tomar la pluma y acabar él mismo esas historias inconclusas cuyos autores prometían continuaciones que no llegaban, pero — según se dice- no lo hace porque otros pensamientos aún más locos estorban su idea (Cervantes, 2004: 29). ¿Para qué contar la historia de otro caballero, si puede convertirse en caballero él mismo? ¿Para qué conformarse con ser mero narrador de una historia, si puede ser su protagonista? A esta misma conclusión llega Enric Marco, según lo

\footnotetext{
${ }^{5}$ El impostor se divide en tres partes y un epílogo. La primera parte lleva por título La piel de la cebolla y en ella Cercas intenta quitar esas capas de mentiras que, como sucede con la cáscara de la cebolla, se van superponiendo de tal manera que ocultan una verdad a la que no es sencillo acceder. En cada capítulo de esta parte se trata de esclarecer qué es verdad y qué es mentira en el relato de Marco y cómo las mentiras se «amasan» con verdades.

${ }^{6}$ Sobre este tema conocemos la referencia a una ponencia de Kalenić Ramšak (2016). La autora nos facilitó gentilmente el resumen, confirmando que el artículo aún no ha sido publicado.
} 
que Cercas expone de la siguiente manera: si Alonso Quijano hubiese optado por escribir una novela de caballerías, «habría vivido vicariamente en ella lo que quiso vivir en la realidad, igual que quizás el Marco real nunca hubiese creado al Marco ficticio si hubiese inventado sus peripecias y las hubiese vivido vicariamente al escribir una ficción» (2014a: 230).

Siendo ya un hombre maduro y habiendo ejercido como mecánico durante gran parte de su vida, Marco decide matricularse en la universidad para estudiar Historia. Si bien es cierto que ya en esa época llevaba años embelleciendo su grisura cotidiana con inventados episodios de heroísmo (Cercas, 2014a: 255), en este momento sucede algo crucial: toma la misma decisión que el hidalgo. ¿Para qué conformarse con estudiar y repetir la historia de otros, si puede protagonizarla?

En su novela, Cercas destaca la tendencia de Marco a hablar de sí mismo en tercera persona, como el hidalgo que, recién devenido caballero, atraviesa el campo de Montiel y va pensando en cómo se contará su historia (Cervantes, 2004: 35). En sus entrevistas con Cercas, Marco deja claro que podría haberse conformado con ser un historiador, pero no había querido «porque la historia es una materia árida, fría y sin vida, una abstracción desprovista de interés para los jóvenes»; entonces decidió hacer algo mejor: «él les presentaba la historia a los chicos en primera persona, palpitante y concreta [...], él les hizo llegar la historia con todo su colorido, su sentimiento, su emoción, su aventura y su heroísmo, él la encarnaba y la revivía ante ellos» (Cercas, 2014a: 39). Marco no quiere ser el novelista de una historia ajena, quiere ser el protagonista, el héroe de una historia que merezca ser contada, por él y por todos: por eso le causa placer tanto relatarse a sí mismo en sucesos increíbles como imaginar lo que otros dirán de él, de su generosidad, de su facilidad de palabra, de su don de gente. Afirma Cercas: «Don Quijote y Marco no son dos novelistas frustrados: son dos novelistas de sí mismos; nunca se hubieran conformado con escribir sus sueños: ellos quieren protagonizarlos» (2014a: 232).

El recorrido vital del personaje Marco es similar también al de don Quijote. Así como asistimos a una primera parte de la novela cervantina con un protagonista que tiene algunos episodios hazañosos y grandes caídas y frustraciones que no logran, sin embargo, mermar su ánimo y su voluntad, la vida heroica de Marco comienza en forma bastante mesurada. Primero se construye a sí mismo como un joven que miente sobre su edad para incorporarse al ejército republicano durante la Guerra Civil y debe luego abandonar el campo de batalla por una herida de guerra. Una vez iniciada la dictadura franquista, Marco afirma haber desarrollado una modesta pero arriesgada actividad de resistencia. Finalmente, llega el esperado reconocimiento, cuando alcanza la secretaría general de la CNT. Cercas lo explica de la siguiente forma:

...en la primera parte don Quijote se inventa los prodigios caballerescos que le ocurren, confunde molinos con gigantes y ventas con castillos, mientras que en la segunda parte los prodigios ocurren de verdad, o así lo cree don Quijote, que enamora a doncellas, asiste a naufragios, oye hablar a cabezas encantadas y lucha en combate singular con otros caballeros andantes; igualmente, sobre todo en la segunda mitad de los años setenta, cuando era secretario 
general de la CNT, Marco acabó viviendo lo que había imaginado, acabó convertido en un líder obrero, enfrentándose a la policía y siendo golpeado por ella. (2014a: 230)

Hasta aquí, el inicio de un sueño de heroicidad que comienza a concretarse. Pero, transcurridos unos veinte años de la muerte de Franco, empieza a desarrollarse en España lo que Cercas denomina «la industria de la memoria» ${ }^{7}$ (2014a: 279). El interés por reconstruir el pasado, del que hasta hacía unos pocos años nadie quería hablar, cobra fuerza y se transforma en un negocio cuyo beneficio no es económico sino moral $^{8}$.

Así como la industria del entretenimiento «genera kitsch, mentiras estéticas, un arte que no es arte sino sucedáneo de arte, la industria de la memoria genera una memoria embustera, sentimentaloide y falsamente heroica: puro cartón piedra, puro kitsch» (Cercas, 2014b, párr. 12). Esta sustitución es, sin embargo, fácilmente aceptada porque, al ocultar la complejidad de la realidad, la hace más digerible. Se abona, así, el terreno para la impostura ${ }^{9}$. En este contexto Marco alcanza su apoteosis.

El Marco de esta etapa, el que preside la Amical de Mauthausen y se harta de dar charlas en las escuelas y discursos en los que conmueve hasta las lágrimas a los políticos más importantes del momento es el Quijote de la segunda parte, que llega al palacio de los duques y siente que «aquel fue el primer día que de todo en todo conoció y creyó ser caballero andante verdadero, y no fantástico, viéndose tratar del mesmo modo que él había leído se trataban los tales caballeros en los pasados siglos» (Cervantes, 2004: 784). El lector asiste entre incrédulo y compasivo a los relatos de un Marco que a sus ochenta años se sentía aún capaz de enamorar a jovencitas que le lanzaban miradas sugestivas, como «altisidoras» que no atendían a las diferencias de edad ni al hecho de que su corazón tuviera dueña.

Cercas recoge y desarrolla en El impostor varias similitudes que de alguna forma fundamentan la afirmación hecha, años antes, en su artículo «Yo soy Enric Marco»:

...el hombre es un animal que miente: la vida en sociedad suele exigir esa dosis de mentira que llamamos educación (y que sólo los hipócritas confunden con la hipocresía); Marco exageró y pervirtió monstruosamente esa necesidad humana. En este sentido se parece a don Quijote o a Emma Bovary, otros dos grandes mentirosos. (Cercas, 2009, párr. 2)

\footnotetext{
${ }^{7}$ Para profundizar sobre la autoficción de Enric Marco y su vínculo con la «industria de la memoria», remitimos a Quílez Esteve (2017).

${ }^{8}$ La memoria como industria se encuadra dentro de lo que Todorov (2000) llama «abusos de la memoria». El recuerdo que se resiste a desprenderse de su carga afectiva individual no logra constituirse como «ejemplar», sino que se afirma en su singularidad. En este sentido, no colabora a la posible reparación del daño, por el contrario, prolonga la deuda simbólica: «sacralizar la memoria es otro modo de hacerla estéril» (2000: 23).

${ }^{9}$ Afirma Elizabeth Jelin (2002: 37): «Las vivencias individuales no se transforman en experiencias con sentido sin la presencia de discursos culturales, y éstos son siempre colectivos». Remitimos a esta autora para ampliar la reflexión sobre el papel que tanto la sociedad en su conjunto como el Estado desempeñan en el lugar que cada época asigna a la memoria. Otros estudios ineludibles para reflexionar sobre la memoria colectiva, su interpretación y sus usos son Pierre Nora (1992) y Tzvetan Todorov (2000).
} 
Como si necesitara justificar tal afirmación, enumera varios rasgos comunes: la inconformidad con la propia existencia; el impulso de cambiar, de reinventarse; su condición de narcisistas, que los hace ocultarse tras un personaje heroico para no reconocerse tal como son; el hambre de gloria; la necesidad de ser queridos y reconocidos; el gusto por la palabra; la fantasía y la imaginación.

Pero a pesar de las similitudes, existen diferencias fundamentales. Detrás de cada una de las analogías entre Marco y don Quijote que presenta el texto, hay una duda que está latente: ¿realmente son comparables?, ¿realmente Marco no hizo daño a nadie, sino que se salvó a sí mismo gracias a la ficción, como lo hace Alonso Quijano ${ }^{10}$ ? ¿Es Marco un Quijote del siglo XX?

Intentaremos proponer en qué aspectos sí y en cuáles no. Marco es un ser que en ciertos momentos genera desprecio, en otros mueve a compasión y en otros se erige como un ser excepcional: «Es el puto amo» le dice Raül, hijo de Javier Cercas, a su padre (Cercas, 2014a: 61). El lector queda así sumergido en esa zona de ambigüedad que el autor llama «punto ciego» ${ }^{11}$, con Marco navegando entre el ingenio y la impostura. Por un lado, como afirma Vargas Llosa, «los hombres no están contentos con su suerte y casi todos - ricos o pobres, geniales o mediocres, célebres u oscuros - quisieran una vida distinta de la que viven» (2002: 5), y en eso Marco no se diferencia de Alonso Quijano. Pero la impostura, según definición de la RAE es un «engaño con apariencia de verdad» (DLE). He aquí una gran diferencia: «A don Quijote nadie se lo tomaba en serio, no engañaba a nadie; en cambio, Marco, engañó a todo el mundo» ${ }^{12}$ (Cercas, 2014a: 61).

Volvamos, como ejemplo de esta diferencia, a los sucesos que se desarrollan en el palacio de los duques. En este episodio don Quijote está viviendo a pleno aquello que soñó vivir, pero tanto los duques como los criados que toman parte en la «puesta en escena» saben bien la condición del caballero. Don Quijote no engaña a nadie: se engaña. Él decide convencerse a sí mismo y, cuando realiza su transformación, no está pensando en lo que resulte creíble, sino en lo que lo satisfaga completamente. Una vez que los demás personajes reconocen el mecanismo tan particular de su locura, también ellos pueden engañarlo. Lo hacen, por ejemplo, el cura y el barbero en la primera parte, cuando recurren al ardid del encantamiento, tanto para justificar la desaparición de los libros, al inicio, como para obligarlo a regresar a su casa, al final. Lo hacen, ya en la segunda parte, el bachiller, los

\footnotetext{
${ }^{10}$ Novell (2011) explica los esfuerzos que Europa ha realizado durante los últimos años para la recuperación de la memoria y reflexiona sobre cómo las mentiras y los falsos testimonios atentan contra este objetivo y contribuyen al negacionismo.

${ }^{11}$ Cercas define el «punto ciego» como «una pregunta sin respuesta, un enigma irresuelto» y agrega: «Ésa es la paradoja que define las novelas de punto ciego; también todas o casi todas mis novelas. El mecanismo narrativo que las rige es en el fondo semejante. En algún momento de su desarrollo se formula una pregunta, y el resto de la novela consiste, de una forma más o menos visible o secreta, en un intento de responderla, hasta que al final la respuesta es que no hay respuesta» (2015a: 54). Por eso no cabe esperar que en El impostor se dé una respuesta inequívoca al enigma de quién es Marco.

${ }^{12}$ Aun habiéndose descubierto su impostura, Marco insistió en defender el sistema mitómano que había creado, como puede verse en Blanchar y Antón (2005).
} 
duques y aun el propio Sancho al «encantar» a Dulcinea. El artificio de don Quijote es tan transparente que permite a los demás entrar a formar parte del mundo que el caballero ha creado.

Marco, por el contrario, antes que engañarse a sí mismo, pretende engañar a los otros, por eso sus mentiras - afirma Cercas - están construidas a partir de verdades, con una deliberada intención de hacerlas creíbles, y se van entrelazando unas y otras de tal forma que en algún momento se llega a la conclusión de que es imposible conocer la verdad sobre ciertos aspectos de su vida. Tal vez por eso resulta tan importante y esclarecedor para el novelista el descubrimiento realizado durante la investigación que desarrolla en el proceso de escritura de El impostor. Marco había falsificado el documento probatorio de su ingreso al campo de Flossembürg y usurpado el número de prisionero que pertenecía en realidad a Enric Moner $^{13}$

Hacia el final de la novela se narra este acontecimiento impactante para el autor: Marco no solo había maquillado su realidad, no había sido solo una víctima que se dejó llevar por la admiración que despertaba en los demás su historia y que, impulsada por ese entusiasmo, fue decorando con toques cada vez mayores de heroísmo su vida, hasta convertirse, casi sin darse cuenta, en el gran héroe que llegó a sentirse. Antes bien, hubo en él un creciente interés por cuidar minuciosamente el alcance y la verosimilitud de sus mentiras, que lo llevó incluso a manipular documentos ${ }^{14}$. Un pobre hidalgo viejo y seco de carnes convertido en héroe resulta inverosímil, la impostura de Marco no lo es.

Los personajes tienen mucho en común, no hay dudas, pero tienen también una diferencia esencial que podríamos formular de la siguiente manera: el hidalgo es ingenioso, Marco es impostor, es decir, «no es una versión encarnada de la actividad literaria; es una persona real, histórica» que «mintió sobre sus orígenes, sobre su identidad y sobre sus vivencias durante la guerra y el franquismo español» (Mansilla, 2017: 300). Afirma Cercas que Marco «tiene éxito donde don Quijote fracasa: así como Alonso Quijano nunca engañó a nadie y todo el mundo sabía que no era más que un pobre hombre que se creía un héroe caballeresco, Marco convenció a todo el mundo de que el Marco ficticio era el Marco real» (2014a: 231).

\footnotetext{
${ }^{13}$ El prisionero 6448, número del cual se apropia Marco, era en realidad el figuerense Enric Moner. En el registro de entrada a Flossembürg su apellido aparece escrito, por error, sin la «r»: «Moné». Esta circunstancia fue aprovechada por el impostor, que explotó la similitud entre los nombres.

${ }^{14}$ En su visita a los archivos de Flossembürg, Cercas lleva consigo la fotocopia del registro que Marco había entregado a la Amical de Mauthausen. Su propósito es averiguar si la confusión entre los apellidos había sido fruto de la casualidad, es decir, si «el tipo que escribió el nombre de Moner lo escribió de tal manera que parece el nombre de Marco» (Cercas, 2014a: 421) o había sido forzada por el impostor. Para el novelista, una cosa es que Marco encontrase «este regalo de los dioses, que le permitía rematar su impostura, y otra cosa es que el regalo se lo hiciera él» (Cercas, 2014a: 421). Así descubre la única prueba falsa, deliberadamente manipulada para hacer creíble el engaño.
} 
A lo largo de su vida, Marco se reinventa varias veces, pero Cercas destaca dos:

La primera vez lo hizo a mediados de los años cincuenta y lo hizo a la fuerza: entonces cambió de oficio y de ciudad, cambió de mujer y de familia y hasta de nombre [...]. La segunda gran reinvención de Marco se produjo a mediados de los años setenta, cuando Franco acababa de morir y empezaba a abrirse paso la democracia, pero esta vez Marco se reinventó porque quiso y sobre todo se reinventó mejor. (2014a: 190)

La primera reinvención de Marco sería la que más se asemeja a la de Alonso Quijano: hay un cambio de nombre y de condición que tendrá consecuencias en su vida futura. En la segunda reinvención, Marco da un paso más y decide «cambiar también su pasado» (Cercas, 2014a: 190) y comienza a crear un relato tan convincente que quienes lo escuchaban, particularmente los jóvenes entusiasmados por el fin del franquismo, «lo consideraran no solo una persona excepcional, sino un auténtico héroe» (Cercas, 2014a: 194). Cabría aquí destacar el uso del adjetivo «auténtico» porque, como decíamos, es la apariencia de verdad lo que, a diferencia de lo sucedido con don Quijote, transforma a Marco en un impostor. Por eso el consejo que Anna Maria Garcia, su compañera en la Facultad de Letras, le da a Cercas es: «Lo que hay que hacer con Marco es olvidarlo. Es el peor castigo para ese monstruo de vanidad» (Cercas, 2014a: 19). Así lo hace durante varios años, pero finalmente pesa más otro consejo, el de Vargas Llosa: «¡Marco es un personaje tuyo! ¡Tienes que escribir sobre él!» (Cercas, 2014a: 22). Esto nos conduce al segundo punto de nuestro artículo: el orden en que Cercas elige abordar la historia.

Indiscutiblemente, uno de los grandes temas que aparecen en El Quijote, desde el inicio, es el de la locura. El narrador del capítulo primero sentencia que es la locura de Alonso Quijano la que propicia el nacimiento de don Quijote: «En efecto, rematado ya su juicio, vino a dar en el más extraño pensamiento que jamás dio loco en el mundo» (Cervantes, 2004: 30). Así elige Cervantes iniciar su historia: presentando el proceso de locura del hidalgo que se transformará en caballero. En cuanto a Enric Marco, en la novela se plantea la duda sobre su sanidad mental — «Marco vive en un mundo de fantasía, más interesante y más divertido que la realidad. Eso es estar loco, ¿no?» (Cercas, 2014a: 56)pero se concluye que es sí un narcisista, pero no un loco. Sin embargo, Cercas comienza también por allí: Marco no está loco, pero sí lo estuvo su madre. Al igual que en El Quijote, lo primero que se aborda de la vida de Marco es el tema de la locura: su nacimiento es en un hospital psiquiátrico.

Se da paso entonces a otra gran coincidencia entre ambos personajes: la soledad. Con su madre internada en el manicomio, Marco vivió su infancia con un padre ausente y una madrastra alcohólica, que además era analfabeta y lo obligaba a leerle las novelas que había en la casa. Así, como Alonso Quijano, Marco supo pasarse los días «de turbio en turbio» leyéndole a su madrastra clásicos de Víctor Hugo, de Balzac, de Vargas Vila y, por supuesto, de Cervantes. La lectura lo rescata de una rutina en la que no hay nada de heroico - ni siquiera nada que lo humanice-, y lo pone, aunque sea momentáneamente, a salvo de los castigos a los que lo sometía la esposa de su padre. En las entrevistas con Cercas, Marco solo 
recuerda dos modos de interacción con su madrastra: los momentos en los que él le leía y aquellos en los que ella lo castigaba (Cercas, 2014a: 46). "La ficción salva» se repite como una especie de leitmotiv en El impostor; podríamos pensar que en Marco esto funciona desde su infancia en un sentido muy básico: lo salva del castigo y se convierte en un elemento de protección física y psíquica.

La lectura y la soledad son dos aspectos comunes, determinantes tanto para Marco como para Alonso Quijano. La soledad del hidalgo, su falta de realización y el hundimiento en la vida rutinaria que se describe en el capítulo primero lo llevarán a la transformación y lo impulsarán a ese cambio radical, que no persigue solo un objetivo altruista, sino también la gloria personal: «así para el aumento de su honra como para el servicio de su república» (Cervantes, 2004a: 30). En este mismo sentido, Marco hace lo que hace en busca de reconocimiento $\mathrm{y}$, sobre todo, de afecto, porque necesitaba «que le quisieran y que le admiraran. Y no soportaba pasar inadvertido» (Cercas, 2014a: 249). En la soledad de ambos personajes, la lectura se transforma en el único acceso a un mundo que colme sus expectativas, porque el mundo de la ficción «es lo que llena el abismo que hay entre la vida que tenemos y los apetitos que albergamos» (Cruz, 2005). Marco, al igual que Alonso Quijano, «es un lector compulsivo» (Cercas, 2014a: 229), pero además «tiene una mirada miserable de su pasado, que no puede tolerar, que no puede sentir propia, porque lo denigra» (Mansilla, 2017: 295). Por eso no le alcanza con cambiar su futuro, debe cambiar también su pasado.

Sabemos que los libros de caballería inspiran a Alonso Quijano en la búsqueda de aventuras y lo impulsan a «ejercitarse en todo aquello que él había leído que los caballeros andantes se ejercitaban» (Cervantes, 2004: 31). Cercas se pregunta si también Marco lee libros de caballería y, en una de las entrevistas, obtiene la respuesta sobre la influencia de la lectura en la impostura de Marco:

...un día cayó en sus manos un libro que llevaba por título La deportación, publicado en 1969 por la editorial Petronio. Era una traducción del francés de un texto donde se ofrecía una panorámica de los campos nazis. En el libro había un capítulo dedicado a Flossenbürg; en el capítulo había varias fotos del campo [...]. Una de estas imágenes atrajo la atención de Marco. Se trataba de un monumento conmemorativo en el que figuraban el número y la nacionalidad de los prisioneros muertos en el campo; Marco notó que entre ellos había representantes de la mayoría de las naciones de Europa, pero sobre todo que también había españoles, y que eran muy pocos: catorce, concretamente. [...]. Marco me aseguró que, en cuanto vio la mencionada foto, decidió hacerse pasar por un deportado en Flossenbürg. (Cercas, 2014a: 255-256)

Al igual que don Quijote, Marco encuentra en los libros, particularmente en uno - aunque no sea una novela de caballería-, el camino a seguir a la hora de reinventarse.

Un último aspecto se aprecia ya desde el capítulo primero de El Quijote: el caballero andante no puede llamarse Quijano, ni Quijada ni Quesada, sino que debe darse a conocer de manera que declare «muy al vivo su linaje y patria» (Cervantes, 2004: 32). Vemos en la novela de Cercas que el protagonista se presenta sucesivamente como Enrique Durruti, Enric 
Batlle o Enrique Marcos. Sin embargo, desde el inicio se hace hincapié en otra modificación que tiene el mismo valor inaugural que el cambio de nombre en Alonso Quijano: Enric Marco falsea su fecha de nacimiento, la retrasa dos días, lo que le permite presentar sus charlas diciendo siempre: «Soy Enric Marco y nací el 14 de abril de 1921, justo diez años antes de la proclamación de la Segunda República española» (Cercas, 2014a: 27).

Así, Marco transforma esta fecha para convertirla en «alta, sonora y significativa» y Cercas deja planteadas las líneas fundamentales de cómo elegirá contar las similitudes entre los personajes antes de comenzar el relato de sus sucesivas entrevistas con Marco: parte de la locura y la soledad como elementos determinantes de lo que sucederá más adelante en sus vidas y menciona la influencia de la lectura. Finalmente, se detiene en un cambio identitario que, como dijimos anteriormente, tiene un valor simbólico fundacional y es el punto de partida hacia un nuevo ser, como si prefigurara un futuro prometedor. Así como cabe esperar hazañas de quien lleva tan alto nombre como «don Quijote de la Mancha», el nacimiento en una fecha tan relevante, exactamente diez años antes de la proclamación de la República, determina en el personaje de Marco la excepcionalidad de su ser.

Por último, Cercas define su propio rol como narrador: aun desde la convicción de que no será posible, plantea que «Marco había contado ya suficientes mentiras y que por lo tanto ya no podía llegarse a su verdad a través de la ficción sino sólo a través de la verdad, a través de una novela sin ficción o un relato real, exento de invención y de fantasía» (2014a: 23). Esta preocupación del novelista por la verdad en su puja con la verosimilitud nos remite nuevamente al primer capítulo del Quijote, en el que el narrador no se detendrá en conjeturas más o menos verosímiles sobre el nombre del hidalgo porque, según declara, «esto importa poco a nuestro cuento: basta que en la narración dél no se salga un punto de la verdad» (Cervantes, 2004: 28).

Cabría también preguntarse, ¿es Cercas el Cervantes o el Cide Hamete Benengeli de Marco? Decíamos que, así como don Quijote imagina sus hazañas siendo contadas por un sabio encantador, al comienzo de la primera parte, cuando aún no ha realizado - o intentado - ninguna, Marco también se sueña narrado y suple la ausencia del cronista hablando de sí mismo en tercera persona o imaginando lo que otros dirán de él. Pero el mismo don Quijote que en la primera parte fantaseaba con un autor que sacaría a la luz sus proezas, en la segunda se encuentra con que el anhelado historiador existe, con que sus aventuras se cuentan en un libro y que tanto él como su escudero son protagonistas del relato de Cide Hamete Benengeli.

Algo así le sucede a Marco con Cercas: encuentra su narrador, pero él, que tantas veces deseó ser narrado, se niega a que la historia se aparte de cómo la imaginó. Por eso sus encuentros se convierten en un acto de seducción por momentos, en una negociación o en discusiones airadas que terminan con un Marco ofendido que no quiere seguir con las entrevistas. Cercas declara en una entrevista publicada por El País: «el libro es un combate a muerte entre la verdad y la mentira. Y por eso, también, las entrevistas con Marco fueron una batalla campal: porque él quería que yo escribiese una hagiografía que lo justificase o lo redimiese, y yo solo podía contar la verdad» (2015b, párr. 7). Es decir, Cercas sería para 
nosotros el Cide Hamete Benengeli porque, como lo explica el bachiller Sansón Carrasco, «uno es escribir como poeta, y otro como historiador: el poeta puede contar o cantar las cosas, no como fueron, sino como debían ser; y el historiador las ha de escribir, no como debían ser, sino como fueron, sin añadir ni quitar a la verdad cosa alguna» (Cervantes, 2004: 569).

La historia de Marco es difícil de contar; Cercas la define como una historia imposible de escribir (2014a: 41). Al autor le lleva años de idas y vueltas: abandona la idea y la retoma en un sinfín de oportunidades. Porque por un lado, se niega a escribir la hagiografía que Marco esperaba de él, pero por otro tampoco quiere ser el Sansón Carrasco que lo obligue a volver a casa derrotado, para morir de cordura o de realidad. Entonces decide convertirse en Cide Hamete Benengeli y escribir la historia de Marco como el autor arábigo cuenta las aventuras del caballero andante «de la misma manera que él las hizo, sin añadir ni quitar a la historia un átomo de la verdad, sin dársele nada por objeciones que podían ponerle de mentiroso» (Cervantes, 2004: 614).

Y, si diéramos un paso más, acaso también sea el Cervantes detrás de Cide Hamete Benengeli: avanzada la novela, Cercas recuerda aquel pasaje del final de El Quijote en el que Cervantes hace hablar a su pluma, para declarar que ella y don Quijote habían nacido el uno para el otro. Entonces se produce una especie de revelación que lo lleva a una conclusión tan osada que parece más digna de Marco o de don Quijote que del propio Cercas, pero cuyo valor poético alcanza para justificarla:

Marco había construido a lo largo de casi un siglo, la mentira monumental de su vida no para embaucar a nadie, o no solo para eso, sino para que un escritor futuro la descifrase con su ayuda y luego la contase y la diese a conocer por el mundo y al final pudiese hacer hablar a su ordenador como Cervantes hace hablar a su pluma («Para mí solo nació Enric Marco, y yo para él: él supo obrar y yo escribir, solos los dos somos para en uno»). (Cercas, 2014a: 333) 


\section{BIBLIOGRAFÍA}

Blanchar, Clara y Jacinto Antón (2005): «El falso deportado presenta sus mentiras como un apoyo a las víctimas», El País, 12/05/2005. Disponible en línea: https://elpais.com/diario/2005/05/12/espana/1115848817 850215.html.

Cercas, Javier (2009): «Yo soy Enric Marco», El País, 27/12/2009. Disponible en línea: https://elpais.com/diario/2009/12/27/eps/1261898808 850215.html.

- (2014a): El impostor, Barcelona, Random House.

-(2014b): «La memoria histórica se ha vuelto una industria», El País, 15/11/2009. Disponible en: https://elpais.com/cultura/2014/11/12/babelia/1415819975 800516.html. - (2014c): «Lo que hizo Marco lo hizo todo el país», El Periódico, 18/11/2014. Disponible en:https://www.elperiodico.com/es/ocio-y-cultura/20141118/javier-cercas-impostor-enric -marco-3699149.

-(2015a): El punto ciego, Barcelona, Random House.

- (2015b): «Me incluí en el relato para no excluir de él al lector», El País, 20/03/2015. Disponible en: https://www.elpais.com.uy/cultural/me-inclui-relato-excluir-lector.html. - (2017): «Escribo novelas de aventuras sobre la aventura de escribir novelas», El Cultural, 17/02/2017. Disponible en: https://elcultural.com/Javier-Cercas-Escribo-novelas-de-aventuras-sobre-la-aventura-de-e scribir-novelas.

Cervantes, Miguel de (2004). Don Quijote de la Mancha, Lima, Alfaguara.

Cruz Ruiz, Juan (2005): «La verdad y la mentira salen a pelear», El País, 29/11/2005. Disponible en: https://elpais.com/diario/2005/11/30/cultura/1133305204_850215.html.

$D L E=$ Real Academia Española, Diccionario de la lengua española, 23. ${ }^{a}$ ed., [versión 23.4 en línea]. Disponible en: https://dle.rae.es.

Jelin, Elizabeth (2002): Los trabajos de la memoria, Madrid/Buenos Aires, Siglo XXI.

Kalenić Ramšak, Branka (2016): «La realidad y la ficción: El impostor de Javier Cercas y su relación con El Quijote», ponencia inédita del congreso El mundo hispano y/en sus fronteras, Dubrovnik, Croacia.

Lejeune, Philippe (1994): El pacto autobiográfico y otros escritos, trad. Ana Torrent, Madrid, Megazul-Endymion. 
Mansilla, K. (2017): «Historicidad e identidad: una lectura de El impostor de Javier Cercas desde la fenomenología de Merleau-Ponty», Logos, XXVII, 2, pp. 291-301. Disponible en: https://revistas.userena.cl/index.php/logos/article/view/946.

Nora, P. (1992): Les lieux de mémoire, París, Gallimard.

Novell, P. (2011): «El recuerdo del Holocausto y "El caso Marco": deber de memoria, abuso preventivo o memoria para el triunfo», Vanderbilt e-Journal of Luso-Hispanic Studies, VI, pp. 129-153. Disponible en: https://ejournals.library.vanderbilt.edu/index.php/lusohispanic/article/view/3258.

Pozo García, A. (2018): «Personaje de sí mismo: verdad y mentira en la narrativa de Javier Cercas», Impossibilia. Revista Internacional de Estudios Literarios, 15, pp. 82-109.

Quílez Esteve, L. (2017): «Los flecos de la memoria: reconstrucción, autoficción e impostura en el testimonio de Enric Marco», Sociocriticism, XXXII, 1, pp. 147-174.

Todorov, T. (2000): Los abusos de la memoria, Barcelona, Paidós.

Vargas Llosa, Mario (2002): La verdad de las mentiras, Madrid, Alfaguara.

- (2014): «La era de los impostores», El País, 14/12/2002. Disponible en: https://elpais.com/elpais/2014/12/11/opinion/1418316858 779129.html. 